\title{
PGC-1 $\alpha$ regulates the cell cycle through ATP and ROS in CH1 cells ${ }^{* \#}$
}

\author{
Xu-feng $\mathrm{FU}^{\S 1,2}$, Kun $\mathrm{YAO}^{\S 1}$, Xing DU ${ }^{1}$, Yan $\mathrm{LI}^{1}$, Xiu-yu $\mathrm{YANG}^{1}$, \\ Min $\mathrm{YU}^{1}$, Mei-zhang $\mathrm{LI}^{1}$, Qing-hua CUI ${ }^{\dagger \ddagger 1}$ \\ ( ${ }^{1}$ School of Life Sciences, Yunnan University, Kunming 650091, China) \\ $\left({ }^{2}\right.$ School of Medicine, Yunnan University, Kunming 650091, China) \\ 'E-mail: cuiqinghua@ynu.edu.cn
}

Received June 26, 2015; Revision accepted Sept. 14, 2015; Crosschecked Jan. 13, 2016

\begin{abstract}
Peroxisome proliferator-activated receptor- $\gamma$ coactivator $1 \alpha(P G C-1 \alpha)$ is a transcriptional co-activator involved in mitochondrial biogenesis, respiratory capacity, and oxidative phosphorylation (OXPHOS). PGC-1a plays an important role in cellular metabolism and is associated with tumorigenesis, suggesting an involvement in cell cycle progression. However, the underlying mechanisms mediating its involvement in these processes remain unclear. To elucidate the signaling pathways involved in PGC-1 1 function, we established a cell line, $\mathrm{CH} 1 \mathrm{PGC}-1 \alpha$, which stably overexpresses PGC-1 $\alpha$. Using this cell line, we found that over-expression of PGC-1 $\alpha$ stimulated extra adenosine triphosphate (ATP) and reduced reactive oxygen species (ROS) production. These effects were accompanied by up-regulation of the cell cycle checkpoint regulators CyclinD1 and CyclinB1. We hypothesized that ATP and ROS function as cellular signals to regulate cyclins and control cell cycle progression. Indeed, we found that reduction of ATP levels down-regulated CyclinD1 but not CyclinB1, whereas elevation of ROS levels down-regulated CyclinB1 but not CyclinD1. Furthermore, both low ATP levels and elevated ROS levels inhibited cell growth, but PGC-1a was maintained at a constant level. Together, these results demonstrate that PGC-1a regulates cell cycle progression through modulation of CyclinD1 and CyclinB1 by ATP and ROS. These findings suggest that PGC-1a potentially coordinates energy metabolism together with the cell cycle.
\end{abstract}

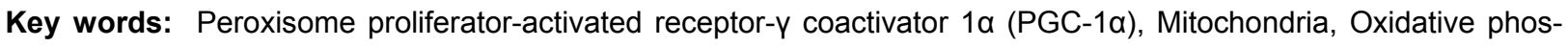
phorylation (OXPHOS), Cell cycle, CyclinD1, CyclinB1 http://dx.doi.org/10.1631/jzus.B1500158

CLC number: Q25

\section{Introduction}

Impairment of mitochondrial oxidative phosphorylation (OXPHOS) leads to depletion of adenosine triphosphate (ATP) and overproduction of reactive oxygen species (ROS), which further induce cell growth defects in mitochondrial disease (Wallace,

\footnotetext{
Corresponding author

$\S$ The two authors contributed equally to this work

* Project supported by the National Natural Science Foundation of China (Nos. 31160237 and 81360310) and the Graduate Student Research Innovation Project of Yunnan University (No. YNUY201455), China

\# Electronic supplementary materials: The online version of this article (http://dx.doi.org/10.1631/jzus.B1500158) contains supplementary materials, which are available to authorized users

(1) ORCID: Xu-feng FU, http://orcid.org/0000-0002-4101-1000

(c) Zhejiang University and Springer-Verlag Berlin Heidelberg 2016
}

2005; Chaturvedi and Beal, 2013). The transcriptional co-activator peroxisome proliferator-activated receptor- $\gamma$ coactivator $1 \alpha(\mathrm{PGC}-1 \alpha)$ is a key regulator of signaling pathways that promote mitochondrial biogenesis and bioenergetics in cardiomyocytes, and PGC-1 $\alpha$ regulates peroxisome proliferator-activated receptor $\alpha(\mathrm{PPAR} \alpha)$ to enhance the transcription of mitochondrial fatty acid $\beta$-oxidation enzymes ( $\mathrm{Wu}$ et al., 1999; Lehman et al., 2000; Vega et al., 2000). It interacts with a broad range of transcription factors, including nuclear hormone receptors, nuclear respiratory factors, and specific transcription factors, to regulate glucose metabolism and response to environmental stimuli such as cold exposure and prolonged starvation (Cannon et al., 1998; Meirhaeghe et al., 2003; Lin et al., 2005). Consistent with these 
roles, it is expressed at high levels in tissues with a high energy demand, such as brain, kidney, cardiac, and skeletal muscle (Lin et al., 2005). Therefore, PGC-1 $\alpha$ dysregulation has critical roles in vascular disease, diabetes, and neurodegenerative disease (Lin et al., 2005). The mechanisms governing cellular energy homeostasis have been an area of active investigation, and numerous studies have implicated PGC-1 $\alpha$ as a key player in the control of energy homeostasis (Rohas et al., 2007). However, the mechanisms by which PGC- $1 \alpha$ exerts this control have remained unclear. Mitochondria are essential for producing the energy source ATP as well as ROS byproducts. ATP generation is finely tuned to match energy demand as an important signal for macromolecule production and DNA synthesis (McBride et al., 2006). Tumor cells, for example, require high levels of ATP for survival, proliferation, and metastasis (Weinberg and Chandel, 2009). Dysfunctional mitochondria are associated with reduced levels of ATP and excessive production of ROS (Pieczenik and Neustadt, 2007). The understanding of ATP and ROS provides significant insight to possible treatments for mitochondrial diseases.

Mitochondrial biogenesis is essential to cell division. It cannot be produced spontaneously and must be inherited at cell division (Shiota et al., 2015). In eukaryotes, the cell cycle is a sequential series of events with checkpoints at the transition from $\mathrm{G} 1$ to $\mathrm{S}$ phase $(\mathrm{G} 1 / \mathrm{S})$ and at the transition from $\mathrm{G} 2$ to $\mathrm{M}$ phase (G2/M) (Löbrich and Jeggo, 2007; Bertoli et al., 2013). CyclinD and CyclinB are members of the cyclin protein family, and interact with cyclin-dependent kinases (CDKs) to regulate the two checkpoints (Malumbres and Barbacid, 2009). Although mitochondrial dysfunction and oxidative stress are heavily involved in various cardiovascular and neurodegenerative diseases, their roles in the cell cycle remain unknown. We hypothesized that mitochondrial OXPHOS capacity is the main driving force of cell cycle progression.

Our work focused on the effects of reverting the PGC-1 $\alpha$ function (into excessive oxidative stress and bioenergetic deficits) on cell cycle, and our aim was to reveal the signaling pathways mediating mitochondrial biogenesis with an emphasis on the PGC- $1 \alpha$ modulator, in order to uncover the new potential pharmacological targets and ameliorate the mitochondrial disease.

\section{Materials and methods}

\subsection{Cell lines and cell culture}

Human kidney epithelial 293T cells were supplied by the Biochemistry and Molecular Biology Laboratory of Yunnan University, China. Mouse embryonic fibroblasts $\mathrm{C} 3 \mathrm{H} / 10 \mathrm{~T} 1 / 2$ clone 8 (CH1) were purchased from the Shanghai Cell Bank of the Chinese Academy of Sciences, China. Cells were cultured with Dulbecco's minimum essential medium (DMEM; Hyclone, Logan, USA) supplemented with $10 \%(\mathrm{v} / \mathrm{v})$ fetal bovine serum (FBS) (Hyclone, Logan, USA) and $1 \%(\mathrm{v} / \mathrm{v})$ penicillin/streptomycin (Hyclone, Logan, USA) at $37^{\circ} \mathrm{C}$ in $5 \% \mathrm{CO}_{2}$.

\subsection{Isolation of human $P G C-1 \alpha$ gene}

Total RNA was extracted from human epithelial 293T cells using the TRIzol reagent (Life Technologies, Foster City, USA). Complementary DNA (cDNA) was synthesized using the SuperScript First-Strand Kit (TaKaRa, Dalian, China). Primers for reverse transcription-polymerase chain reaction (RT-PCR) were designed by Primer Premier 5.0 software to amplify the complete $P G C-1 \alpha$ open reading frame (ORF) specified in the human $P G C$ - $1 \alpha$ gene reference sequence at GenBank (accession No. NM_013261.3). Primer sequences were as follows: PGC-1 $\alpha-B a m H I-F$ : 5'-GGA TCC ATG GCG TGG GAC ATG TGC AAC-3'; PGC-1 $\alpha-S a l I-R:$ 5'-GTC GAC TTA CCT GCG CAA GCT TCT CTG AG-3'. BamHI and SalI restriction enzyme sites are underlined, respectively. For PCR, the reaction mixture contained $20 \mathrm{ng} / \mu \mathrm{l}$ cDNA template, $\mathrm{MgCl}_{2}$, primers, $10 \mathrm{mmol} / \mathrm{L} \mathrm{dNTP}$, $10 \times$ reaction buffer, Taq DNA polymerase, and double distilled water $\left(\mathrm{ddH}_{2} \mathrm{O}\right)$. The PCR reaction was conducted for 30 cycles, with each cycle consisting of steps at $94{ }^{\circ} \mathrm{C}$ for $2 \mathrm{~min}, 94^{\circ} \mathrm{C}$ for $40 \mathrm{~s}, 66^{\circ} \mathrm{C}$ for $30 \mathrm{~s}$, and $72{ }^{\circ} \mathrm{C}$ for $150 \mathrm{~s}$. After 30 cycles, samples were subjected to a final step at $72{ }^{\circ} \mathrm{C}$ for $10 \mathrm{~min}$. PCR products were separated by agarose gel electrophoresis and the $P G C-1 \alpha$ cDNA fragment was purified using a DNA recovery kit (TaKaRa, Dalian, China).

\subsection{Construction of PGC-1 $1 \alpha$ recombinant plasmid}

To construct pMD18T-PGC-1 $\alpha$, we prepared a reaction mixture containing $\mathrm{pMD} 18 \mathrm{~T}$ vector, PGC-1 $\alpha$ DNA, and T-Vector Solution I. Samples were incubated at $16{ }^{\circ} \mathrm{C}$ overnight, and positive clones were 
sent to Shanghai Sangon Co. for DNA sequencing. After sequence confirmation, pMD18T-PGC-1 $\alpha$ and pBABEneo (Addgene, USA) were digested by restriction enzymes BamHI and SalI (TaKaRa, Dalian, China) to construct pBABEneo-PGC-1 $\alpha$. The digested products were purified by a DNA recovery kit and ligated. The ligation mixture was transformed into DH5 $\alpha$ competent cells (TransGen, Beijing, China). PCR was used to screen for positive clones and the recombinant plasmid of pBABEneo-PGC-1 $\alpha$ was sequenced by Shanghai Sangon Co., China.

\subsection{Virus packaging and cellular stable transfection}

Recombinant pBABEneo-PGC-1 $\alpha$ vector, packaging plasmid pCLECO, and X-tremeGENE HP DNA Transfection Reagent (Roche, Basel, Switzerland) were added into $10 \%$ FBS DMEM medium, mixed gently, and incubated at room temperature for $20 \mathrm{~min}$. The mixture was added dropwise into 293T cells in a $10-\mathrm{cm}$ plate. After $48 \mathrm{~h}$, the supernatant containing pBABEneo-PGC- $1 \alpha$ virus was collected and filtered using a $0.45-\mu \mathrm{m}$ filter. $\mathrm{CH} 1$ cells were then infected with the virus. After $48 \mathrm{~h}$ of culture, aminoglycoside antibiotic G418 (Gibco-BRL, Carlsbad, USA) was added into the medium at a final concentration of $600 \mu \mathrm{g} / \mathrm{ml}$ to select CH1 cells with stable expression of PGC- $1 \alpha$. PGC- $1 \alpha$ expression was confirmed by Western blotting (Chen et al., 2014).

\subsection{RNA interference of PGC-1 $\alpha$}

Three double strands of small interference RNAs (siRNAs; 1009, 1523, and 853) fragments of PGC-1 $\alpha$ were synthesized by GenePharma Co. (Shanghai, China). These siRNAs were designed according to the mRNA (NM_013261.3) loci of 1009 (target: 5'-CAC CAC TCC TCC TCA TAA A-3'), 1523 (target: 5'-GGA CAG TGA TTT CAG TAA T-3'), and 853 (5'-GTC GCA GTC ACA ACA CTT A-3'). These siRNA sequences are as follows: 1009, sense 5'-CAC CAC UCC UCC UCA UAA ATT-3' and antisense 5'-UUU AUG AGG AGG AGU GGU GTT-3'; 1523, sense 5'-GGA CAG UGA UUU CAG UAA UTT-3' and antisense 5'-AUU ACU GAA AUC ACU GUC CTT-3'; 853, sense 5'-GUC GCA GUC ACA ACA CUU ATT-3' and antisense 5'-UAA GUG UUG UGA CUG CGA CTT-3'. CH1 cells with PGC-1 $\alpha$ stable expression (CH1 PGC-1 $\alpha$ ) were seeded and cultured until they reached $60 \%$ confluence. A mixture con- taining the PGC- $1 \alpha$ interference fragment and a green fluorescent control for measuring transfection efficiency (FAM fragment) was transfected into $\mathrm{CH} 1$ PGC- $1 \alpha$ cells using X-tremeGENE HP DNA transfection reagent. Transfection efficiency was measured after $48 \mathrm{~h}$.

\subsection{Method of treatment by oligomycin $A$ or hydrogen peroxide}

When cells reached $70 \%$ confluence, they were incubated with oligomycin A (Sigma, St. Louis, USA), an inhibitor of ATP synthase, or hydrogen peroxide (Sangon, Shanghai, China) for varying lengths of time to find the optimal treatment. Oligomycin A was dissolved in ethanol at a concentration of $1 \mathrm{mg} / \mathrm{ml}$ and cells were treated for $6,12,24,36$, and $48 \mathrm{~h}$. The time point of $24 \mathrm{~h}$ was chosen as the optimal time point for reduction of the cellular ATP level. Cells were treated with 100 or $200 \mu \mathrm{mol} / \mathrm{L}$ of hydrogen peroxide for $5 \mathrm{~h}$, a treatment course in which cellular hydrogen peroxide content was high but cell death was not induced. Effects of the treatment on protein expression and cell growth were determined using Western blotting and flow cytometry.

\subsection{Western blot}

Cells were collected and washed twice with phosphate buffer solution (PBS), after which they were incubated in an ice-cold RIPA lysis buffer (Beyotime, Jiangsu, China) on ice for $20 \mathrm{~min}$ and centrifuged at $10000 \mathrm{~g}$ for $15 \mathrm{~min}$ at $4{ }^{\circ} \mathrm{C}$. The supernatant was collected and the protein concentration was quantified with a BCA kit (Dingguo, Beijing, China). Whole cell lysate $(50 \mu \mathrm{g})$ was loaded onto a $12.5 \%$ polyacrylamide gel for sodium dodecyl sulfate polyacrylamide gel electrophoresis (SDS-PAGE), and transferred to a polyvinylidene fluoride (PVDF) membrane with $100 \mathrm{~V}$ constant voltage for $2 \mathrm{~h}$. The membrane was then blocked with $5 \%(0.05 \mathrm{~g} / \mathrm{ml})$ milk and incubated with primary antibody (at 1:1000 (v/v) dilution) at $4{ }^{\circ} \mathrm{C}$ overnight. After being washed 3 times with PBST (PBS solution contain 0.1\% Tween 20), the membrane was incubated with a secondary antibody (at 1:2000 (v/v) dilution) at room temperature for $2 \mathrm{~h}$, and protein was detected with an enhanced chemiluminescence kit (Thermo scientific, Boston, USA). PGC-1 $\alpha$, CyclinD1, and CyclinB1 antibodies were purchased from Cell Signaling 
Technology Co. (CST, Boston, USA), and an antitubulin antibody was obtained from Beyotime Co. (Jiangsu, China) (Chen et al., 2014). To quantify relative protein expression, Western blots were analyzed using ImageJ software.

\subsection{Cell cycle analysis by flow cytometry}

Cells were harvested and washed in cold PBS, then incubated in $50 \mu \mathrm{g} / \mathrm{ml}$ of propidium iodide (PI) solution (containing $0.03 \%$ TritonX-100) at room temperature for $20 \mathrm{~min}$. For each sample, at least $2 \times 10^{5}$ cells $/ \mathrm{ml}$ were analyzed by a BD Accuri C6 flow cytometer (BD Biosciences, San Jose, USA). Cell cycle profiles were calculated by Modfit LT software.

\subsection{Cell viability}

Cells were seeded into 96-well plates. Cell viability was assessed by 3-(4,5-dimethylthiazol-2-yl)5-(3-carboxymethoxyphenyl)-2-(4-sulfophenyl)-2Htetrazolium (MTS) assay every $12 \mathrm{~h}$ during a $60-\mathrm{h}$ period. Cell Titer 96 Aqueous One Solution (Promega, Madison, USA) was added to each well and cells were incubated at $37^{\circ} \mathrm{C}$ for $2 \mathrm{~h}$. The optical density at $490 \mathrm{~nm}\left(\mathrm{OD}_{490}\right)$ was read using a microplate reader (Bio-Rad, Tokyo, Japan).

\subsection{ROS measurement}

Cells were collected and resuspended in PBS at $1 \times 10^{5}$ cells $/ \mathrm{ml}$. MitoSOX Red dye $(5 \mu \mathrm{mol} / \mathrm{L}$; mitochondrial ROS specific, Invitrogen-Life Technologies, New York, USA) was added to the cells, after which they were incubated at $37{ }^{\circ} \mathrm{C}$ for $30 \mathrm{~min}$. Untreated cells served as negative controls. Red fluorescence was detected using a BD Accuri C6 flow cytometer (BD Biosciences, San Jose, USA) (Hahm et al., 2014; Xu et al., 2015).

\subsection{Comparative assay of ATP}

Cells were collected and resuspended in PBS at $1 \times 10^{6}$ cells $/ \mathrm{ml}$. ATP lysis buffer was added into cells and incubated on ice for $30 \mathrm{~min}$. The cell lysate was centrifuged at $12000 \mathrm{r} / \mathrm{min}$ for $10 \mathrm{~min}$, after which ATP levels in the supernatant were measured using an ATP assay kit (Beyotime, Jiangsu, China). Bioluminescence was measured on a Pi-102 fluorescence luminometer (Hygiena, New York, USA). Cellular ATP content (nmol/L) was calculated using an ATP standard and normalized using a BCA protein assay kit (Xiong et al., 2012).

\subsection{Statistical analysis}

Statistical analysis was performed using the SPSS version 16.0 software. All experiments were repeated at least three times and the evaluation data parameters are reported as mean \pm standard deviation (SD).

\section{Results}

\section{1 pBABE-PGC-1 $\alpha$ plasmid construction}

Retroviral vector $\mathrm{pBABEneo}$ was used to construct a pBABE-PGC- $1 \alpha$ recombinant plasmid containing the $P G C-1 \alpha$-coding sequence. PCR was used to confirm the presence of the $P G C-1 \alpha$-coding sequence, which had an expected PCR product size of 2396 bp (Fig. 1a). We then sub-cloned PGC-1 $\alpha$ cDNA into a pMD18T plasmid containing BamHI and SalI restriction sites to construct pMD18TPGC-1 $\alpha$. Positive clones were sequenced using pMD18T primers and found to have the correct PGC-1 $\alpha$ cDNA sequence. Then pMD18T-PGC-1 $\alpha$ (Fig. 1b, Lane 1) and pBABEneo were digested with BamHI and SalI. Agarose gel electrophoresis showed that the correct product size was obtained after digestion with the two enzymes (Fig. 1b, Lane 2). The digested PGC- $1 \alpha$ fragment and pBABEneo were purified using a DNA recovery kit and ligated with T4 ligase. The ligation product of pBABEneo-PGC-1 $\alpha$ (about 7700 bp in size; Fig. 1c, Lane 1) was confirmed by sequencing and transformed into DH5 $\alpha$ competent cells. Positive bacterial clones were digested and showed the correct product size (Fig. 1c, Lane 2). These results indicated successful construction of the pBABE-PGC- $1 \alpha$ recombinant plasmid.

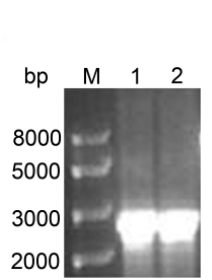

(a)

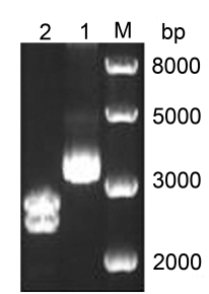

(b)

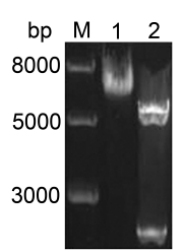

(c)
Fig. 1 Strategy for construction of pBABEneo-PGC-1 $\alpha$ expression vector

(a) Agarose gel analysis of PGC- $1 \alpha$ cDNA PCR product. M: $1 \mathrm{~kb}$ DNA ladder; Lanes 1 and 2: PGC-1 $\alpha$ cDNA. (b) Gel image of pMD18T-PGC-1 $\alpha$ digested with BamHI and SalI. Lane 1: pMD18T-PGC-1 $\alpha$ plasmid; Lane 2: after digestion. (c) Gel image of pBABEneo-PGC-1 $\alpha$ digested by BamHI and SalI. Lane 1: pBABEneo-PGC-1 $\alpha$ plasmid; Lane 2: after digestion 


\subsection{Establishment of cell lines overexpressing PGC-1a or with PGC-1a knockdown}

To make virus particles, 293T cells were co-transfected with pBABEneo-PGC- $1 \alpha$ recombinant plasmid and packaging plasmid pCLECO using $\mathrm{X}$-tremeGENE HP DNA transfection reagent. As a control, cells were transfected with the empty vector pBABEneo. Cells were harvested after $48 \mathrm{~h}$ and PGC-1 $\alpha$ expression was measured using Western blotting. We found that PGC- $1 \alpha$ was highly expressed in pBABEneo-PGC-1 $\alpha$ co-transfected cells but not in cells transfected with the empty control vector. Supernatant containing pBABEneo-PGC- $1 \alpha$ virus or control virus was collected to infect the host $\mathrm{CH} 1$ cells. After infection, $\mathrm{CH} 1$ cells with stable expression of PGC-1 $\alpha$ or control vector were selected in culture media supplemented with the antibiotic G418. As expected, PGC-1 $\alpha$ was expressed at higher levels in pBABEneo-PGC- $1 \alpha$ stable $\mathrm{CH} 1$ cells (PGC- $1 \alpha$ ), compared with cells containing the pBABEneo empty vector (PB) (Fig. 2a). To study the function of PGC-1 $\alpha$, we transfected cells overexpressing PGC-1 $\alpha$ with siRNA ( $\mathrm{Si}$ ) to knock down PGC-1 $\alpha$. In this process, the efficiency of siRNA had been demonstrated in PGC- $1 \alpha$ cells by NC (non-targeting control) and FAM (siRNA has fluorescence) (Fig. 2b). To study the function of PGC-1 $\alpha$, we tested the efficiency of three siRNAs $(1009,1523$, and 853) in PB (Figs. 2c and 2d) and PGC-1 $\alpha$ (Figs. 2e and 2f) cell lines through the PGC-1 $\alpha$ expression level. The level of PGC-1 $\alpha$ expression showed no significant difference between PB and Si groups. However, there is a significant difference between PGC- $1 \alpha$ and Si groups, which could be due to the much lower endogenic PGC-1 $\alpha$ expression in PB cells. The effect of 853 was the best among these three siRNAs (Figs. 2e and 2f), so we chose 853 for subsequent experiments. These results confirmed the cell lines in which various levels of PGC- $1 \alpha$ established, and which in subsequent experiments were used to determine the role of PGC- $1 \alpha$ in mitochondrial function and cell proliferation.

\subsection{Mitochondrial function and cell proliferation in CH1 PGC-1 $\alpha$ cells}

Cellular ROS and ATP contents can be used as markers of proper mitochondrial function. As PGC$1 \alpha$ is an important regulator of mitochondrial function, we sought to determine whether PGC-1 $\alpha$ expression level affects ROS and ATP contents. Using the fluorescent superoxide indicator MitoSOX Red, we found

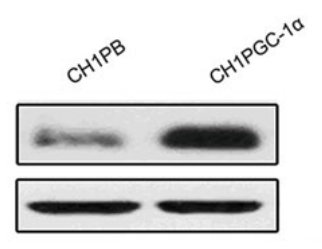

(a)

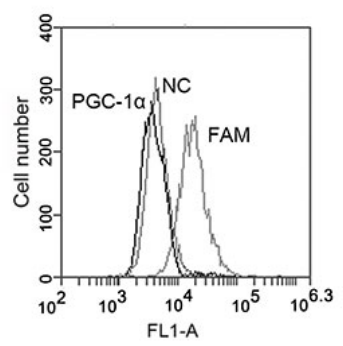

(b)

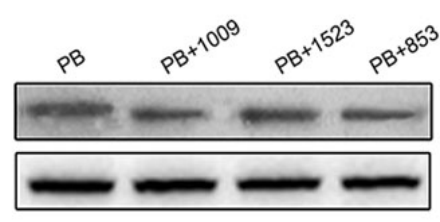

(c)

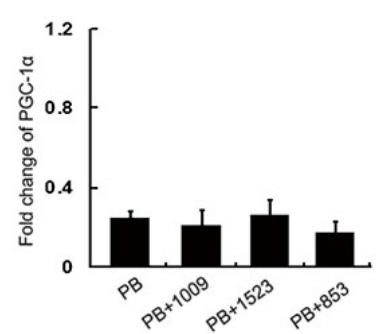

(d)

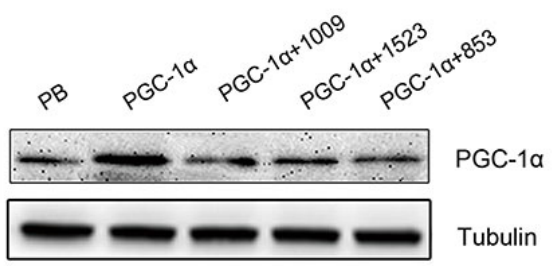

(e)

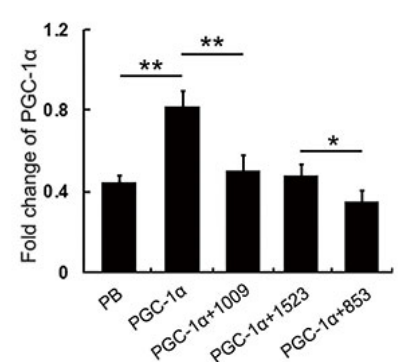

(f)

Fig. 2 Establishment of a stable CH1 cell line expressing PGC-1 $\alpha$ and RNA interference (a) Expression of PGC-1 $\alpha$ protein in PB (pBABEneo empty vector) and PGC-1 $\alpha$ (pBABEneo-PGC-1 $\alpha$ ) cell lines; (b) The efficiency of small interference RNA (siRNA) was detected by flow cytometry (NC as non-targeting control and FAM as efficiency detection with fluorescence); (c) Expression of PGC-1 $\alpha$ protein in PB and PB cells that were interfered by three siRNA (1009, 1523, and 853); (d) Semi-quantification of PGC-1 $\alpha$ protein expression in (c); (e) Expression of PGC-1 $\alpha$ protein in PB, PGC-1 $\alpha$, and PGC-1 $\alpha$ cells that were interfered by three siRNA $(1009,1523$, and 853); (f) Semi-quantification of PGC-1 $\alpha$ protein expression in (e). ${ }^{* *} P<0.01,{ }^{*} P<0.05$. Data are expressed as mean $\pm \mathrm{SD}(n=3)$ 
that ROS levels in PGC-1 $\alpha$ cells were lower than those in PB and Si cells (Fig. 3a). In contrast, ATP assay showed that ATP levels in PGC- $1 \alpha$ cells were higher than those in PB and Si cells ( $P<0.01$; Fig. 3 b). These results showed that PGC- $1 \alpha$ reduced ROS and increased ATP levels in a concentration-dependent manner. To determine the role of PGC- $1 \alpha$ in cell growth, cell proliferation rates were determined using an MTS kit. PGC- $1 \alpha$ cells proliferated significantly faster than PB cells and Si cells during the time course examined (Fig. 3c). These results suggest that $\mathrm{CH} 1$ PGC- $1 \alpha$ cells can be used as a model for studying the underlying mechanisms by which PGC- $1 \alpha$ regulates cell growth.

\subsection{Comparative analysis of cell cycle profile}

In order to check whether PGC-1 $1 \alpha$ functions on cell growth and cell proliferation, the cell cycle profiles of PGC-1 $\alpha$, PB, and Si cell lines were measured by flow cytometry. We observed greater $\mathrm{S}$ phase accumulation in PGC- $1 \alpha$ cells $((53.50 \pm 2.35) \%)$ than in PB cells $((48.14 \pm 1.32) \%)$ or $\mathrm{Si}$ cells $((47.32 \pm 1.27) \%)$ (Figs. $4 \mathrm{a}$ and $4 \mathrm{~b}$ ). There was just a slight difference in G2/M progression between PGC-1 $\alpha$ and Si groups. The CyclinD1 and CyclinB1 play important roles in cell cycle regulation through their interactions with CDKs. Specifically, CyclinD1 regulates the transition from $\mathrm{G} 1$ to $\mathrm{S}$ phase, whereas CyclinB1 regulates the transition from $\mathrm{G} 2$ to $\mathrm{M}$ phase. We found that both CyclinD1 and CyclinB1 were overexpressed in $\mathrm{CH} 1$ PGC-1 $\alpha$ cells (Figs. 4c-4e). These results were also confirmed by immunofluorescence images which are presented in supplementary information (Fig. S1). Up-regulation of CyclinD1 could contribute to the $\mathrm{S}$ phase accumulation. However, the up-regulated CyclinB1 did not change the proportion of $\mathrm{G} 2 / \mathrm{M}$ phase cells. There are two possibilities: the upregulated CyclinB1 was located in the cytoplasm instead of the nucleus, or it remained dephosphorylated. Both of them block the activity of CyclinB1. More experiments need to be conducted to determine which is the cause.

\subsection{Analysis of cell cycle after oligomycin A treatment}

There are several possible mechanisms by which PGC- $1 \alpha$ could promote S phase accumulation. PGC$1 \alpha$ may directly upregulate CyclinD1 and CyclinB1 to increase $\mathrm{S}$ phase accumulation and accelerate cell growth. However, another possibility is that the increased ATP or the decreased ROS induced by PGC- $1 \alpha$ serve as signals to regulate CyclinD1 and CyclinB1. An increasing body of evidence indicates that ROS and ATP are important players in various cellular regulation pathways. As such, we sought to externally manipulate ATP and ROS levels to determine their influence on CyclinD1 and CyclinB1.

To decrease ATP generation, we blocked the mitochondrial respiratory chain by culturing cells in media supplemented with oligomycin A for $24 \mathrm{~h}$. Interestingly, we found that CyclinD1 was downregulated by oligomycin A treatment in a dosedependent manner (Figs. 5a and 5b), whereas CyclinB1 showed no significant change (Figs. 5a and 5c). In addition, PGC- $1 \alpha$ expression was maintained at a constant level in each treatment condition (Fig. 5d). Further analysis of the cell cycle profile showed less $\mathrm{S}$ phase accumulation in PGC- $1 \alpha$ cells $((56.47 \pm 3.26) \%)$ after oligomycin A treatment than in untreated cells ((30.94 \pm 1.78$) \%$; Figs. 5e and 5f). These results suggest that PGC-1 $\alpha$ regulates CyclinD1, but not CyclinB1, through its influence on ATP.

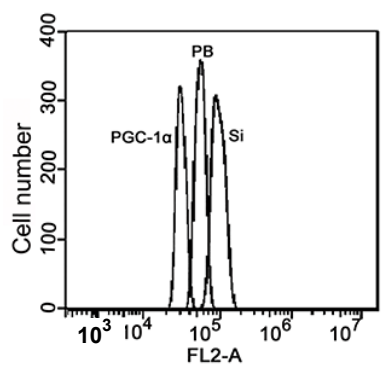

(a)

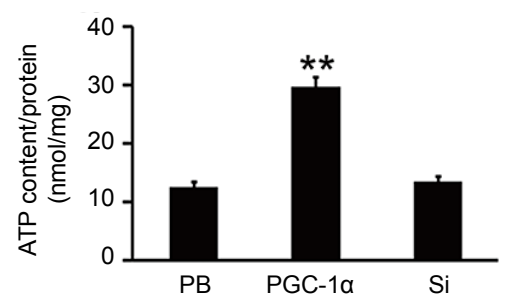

(b)

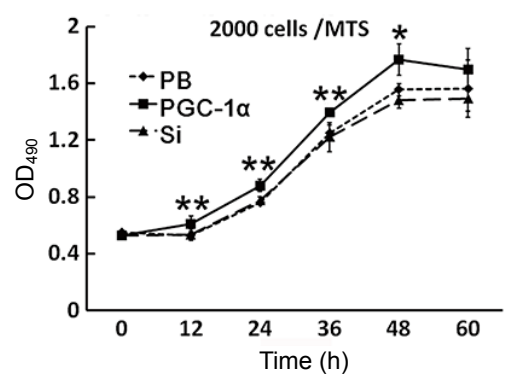

(c)

Fig. 3 Mitochondrial function and cell viability assay in CH1 cells (a) ROS level indicated by MitoSOX Red fluorescence (analyzed by flow cytometry); (b) Assay of ATP content; (c) Viability curve by MTS kit. ${ }^{* *} P<0.01,{ }^{*} P<0.05$. Data are expressed as mean $\pm \mathrm{SD}(n=3)$ 

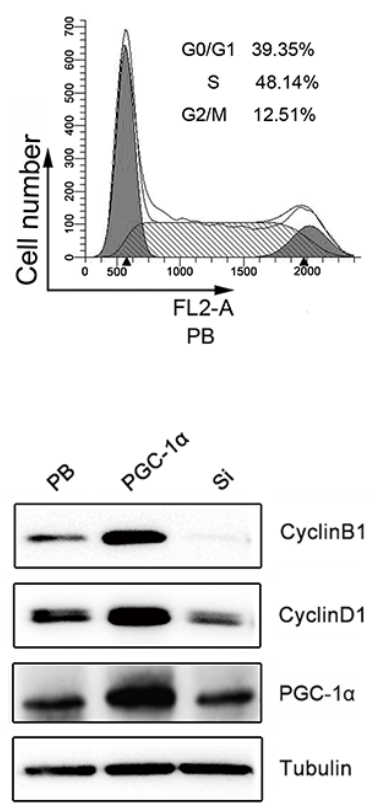

(c)

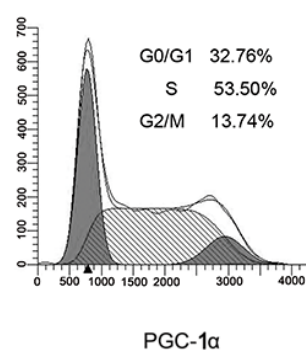

(a)

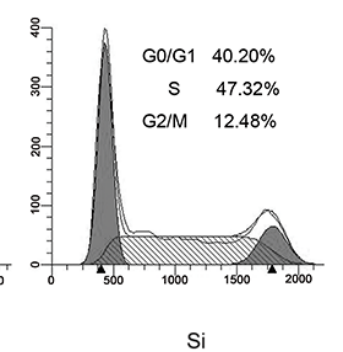

Si

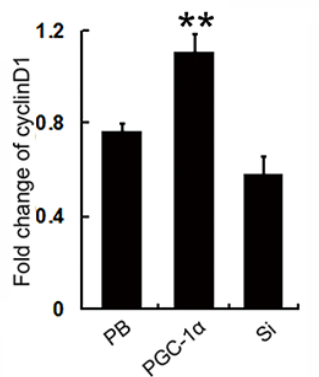

(e)

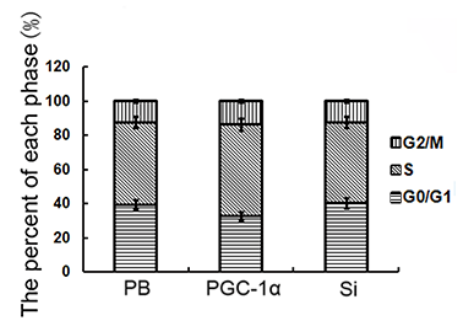

(b)

Fig. 4 Cell cycle profiles and CylinD1/B1 expression in $\mathrm{CH1}$ cells

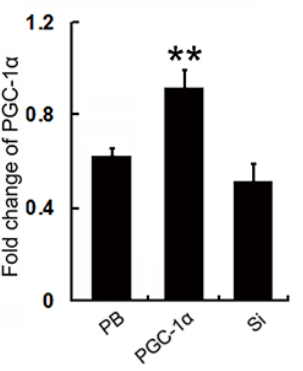

(f)

Cell cycle profiles (a) and phase proportions (b) of PB, PGC-1 $\alpha$, and Si cells; (c) The expressions of CyclinD1 and CyclinB1 in PB, PGC-1 $\alpha$, and Si cells were detected by Western blotting; (d) Semi-quantification of CyclinB1 protein expression in (c); (e) Semi-quantification of CyclinD1 protein expression in (c); (f) Semi-quantification of PGC-1 $\alpha$ protein expression in (c). ${ }^{* *} P<0.01$. Data are expressed as mean $\pm \mathrm{SD}(n=3)$

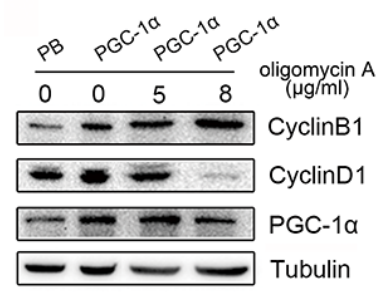

(a)

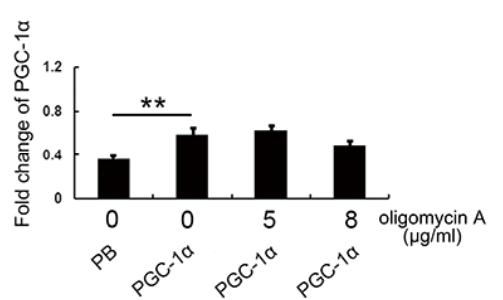

(d)

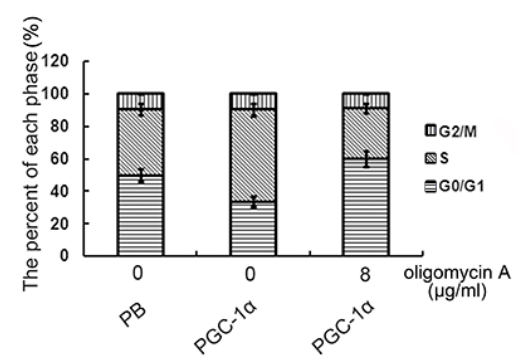

(f)

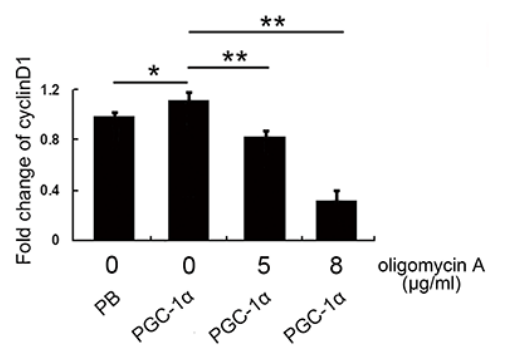

(b)

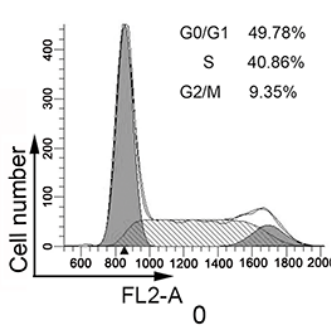

PB

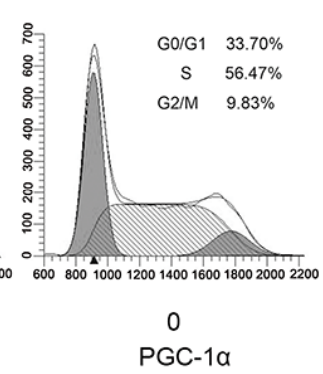

(e)

Fig. 5 Cell cycle profiles and changes in CyclinD1/B1 levels in CH1PGC-1 $\alpha$ after $24 \mathrm{~h}$ of oligomycin A treatment

(a) Protein expressions of CyclinB1, CyclinD1, and PGC-1 $\alpha$. PGC-1 $\alpha$ cells were treated with oligomycin $\mathrm{A}(0,5$, and $8 \mu \mathrm{g} / \mathrm{ml})$. $\mathrm{PB}$ was used as a control for PGC-1 $\alpha$. Semi-quantification of CyclinD1 (b), CyclinB1 (c), and PGC-1 $\alpha$ (d) in (a). (e) Profiles of cell cycles. (f) The percentage of CH1 cells in each phase. ${ }^{* *} P<0.01,{ }^{*} P<0.05$. Data are expressed as mean \pm SD $(n=3)$ 


\subsection{Analysis of cell cycle after $\mathrm{H}_{2} \mathrm{O}_{2}$ treatment}

We found that ROS levels were low in $\mathrm{CH} 1$ PGC- $1 \alpha$ cells (Fig. 4a). To explore whether ROS function as a signal to influence cell cycle progression, we added exogenous $\mathrm{H}_{2} \mathrm{O}_{2}$ to increase ROS and detected the expression of CyclinB1 and CyclinD1. Western blotting (Fig. 6a) showed $\mathrm{H}_{2} \mathrm{O}_{2}$ exposure decreased CyclinB1 (Fig. 6b), but not CyclinD1 (Fig. 6c). Importantly, we observed that PGC-1 $\alpha$ was maintained at a constant level in each treatment condition (Fig. 6d), suggesting that CyclinB1 was downregulated by $\mathrm{H}_{2} \mathrm{O}_{2}$, and not by PGC- $1 \alpha$. Finally, cell cycle profiling showed that increased $\mathrm{H}_{2} \mathrm{O}_{2}$ inhibited cell growth, as $(56.15 \pm 2.31) \%$ of untreated PGC- $1 \alpha$ cells were in $\mathrm{S}$ phase, compared with $(31.37 \pm 1.33) \%$ of cells treated with $100 \mu \mathrm{mol} / \mathrm{L}$ of $\mathrm{H}_{2} \mathrm{O}_{2}$ (Figs. 6e and 6f).

\section{Discussion}

A large body of experimental evidence demonstrates that mitochondrial OXPHOS significantly contributes to ATP supply and ROS production. However, fewer papers reported that association of the mitochondrial respiratory chain complexes form higher supramolecular structures, which are called mitochondrial respiratory supercomplexes. These supercomplexes can take electrons from $\mathrm{NADH}$ to reduce oxygen (Acín-Pérez et al., 2008; Althoff et al., 2011; Vartak et al., 2013). Mitochondria exert a pivotal role in mediating cell proliferation and apoptosis (Zhang et al., 2007), and mitochondrial dysfunction is a hallmark of many genetic diseases and tumor progression. As mitochondrial biogenesis can be manipulated to compensate for deficits in energy,

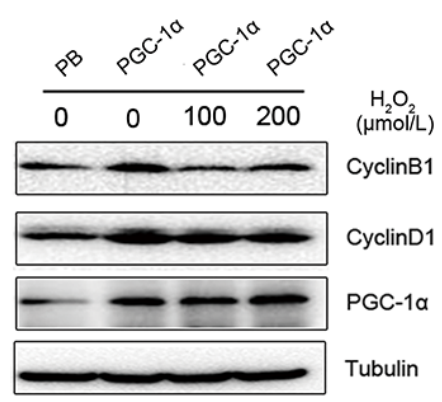

(a)
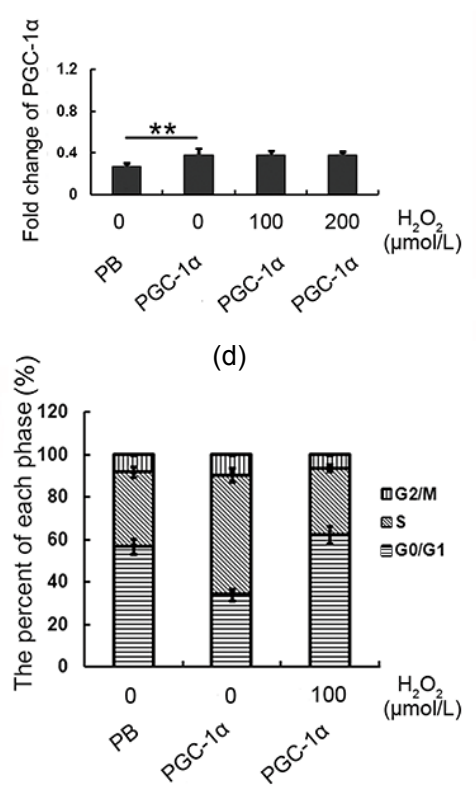

(f)

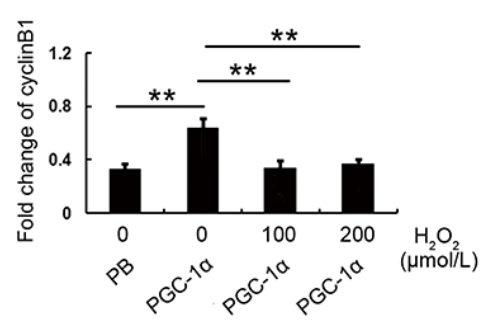

(b)

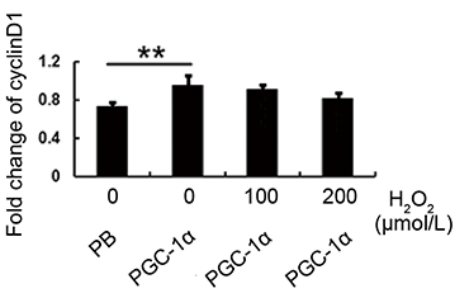

(c)

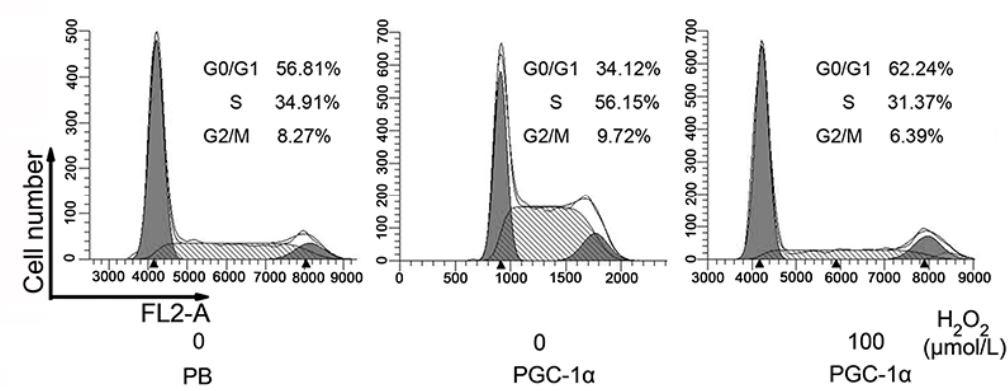

(e)

Fig. 6 Cell cycle profiles and changes in CyclinD1/B1 in CH1-PGC-1a after $5 \mathrm{~h}$ of $\mathrm{H}_{2} \mathrm{O}_{2}$ exposure

(a) Probe for CyclinB1, CyclinD1, and PGC-1 $\alpha$. PGC-1 $\alpha$ cells were exposed to $\mathrm{H}_{2} \mathrm{O}_{2}(0,100$, and $200 \mu \mathrm{mol} / \mathrm{L})$. PB served as a control for PGC- $1 \alpha$. Semi-quantification of CyclinD1 (b), CyclinB1 (c), and PGC-1 $\alpha$ (d) in (a). (e) Profile of cell cycle. (f) The percentage of $\mathrm{CH} 1$ cells in each phase. ${ }^{* *} P<0.01$. Data are expressed as mean \pm SD $(n=3)$ 
it has been recently proposed as a potential therapeutic target for treatment of mitochondrial disease (Valero, 2014). Recently, several independent groups identified PGC- $1 \alpha$ as a key modulator of mitochondrial OXPHOS to increase the level of ATP (Rohas et al., 2007; Won et al., 2010), and suggested that PGC-1 $\alpha$ may be involved in aging and tumorigenesis. Furthermore, both mitochondrial dysfunction and downregulation of PGC- $1 \alpha$ are present in Huntington's disease, Alzheimer's disease, and Parkinson's disease, providing further support for a relationship between mitochondrial function and PGC-1 $\alpha$ (Miraglia et al., 2015; Rice et al., 2015). Although a mitochondrial origin for these diseases has been proposed (Falk et al., 2015), regulation of mitochondrial biogenesis in the context of these diseases has not been extensively studied. In this study, we established cell lines in which PGC-1 $\alpha$ was overexpressed or knocked down to investigate the signaling pathways by which PGC- $1 \alpha$ could influence cell growth.

We found that elevated PGC-1 $\alpha$ expression increased ATP level, reduced ROS production, and accelerated cell proliferation. The increase of ATP could be due to more mitochondria content (mitochondrial content was detected with the result presented in Fig. S2). PGC-1 $\alpha$ promotes mitochondrial biogenesis through expression of mitochondrial proteins and activation of p38/MAPK pathway (AcínPérez et al., 2008; Luckhart et al., 2013). These results confirmed that PGC- $1 \alpha$ has an important role in prompting ATP production and clearing excessive ROS, and mitochondrial respiratory supercomplexes also enhance ATP and decrease ROS through structure variant, so we suggested that PGC- $1 \alpha$ may be a positive regulator of mitochondrial respiratory supercomplex formation, but the mechanism remains unclear. A major focus of our study was to address the influence of PGC-1 $\alpha$ in the context of mitochondrial function and cell cycle progression. We hypothesized that PGC- $1 \alpha$ regulates cell cycle proteins and triggers cell proliferation indirectly, through its modulation of ATP and ROS levels.

To test our hypothesis, we manipulated mitochondrial function to attenuate ATP production and accumulate ROS in order to determine whether they would reduce the oncogenic properties of PGC-1 $\alpha$ cells. Importantly, PGC-1 $\alpha$ levels remained constant throughout treatment. The electron transport chain (ETC) is responsible for OXPHOS-mediated mitochondrial respiration (Chen et al., 2010). Our results demonstrated that oligomycin A, a classic mitochondrial complex-III inhibitor, blocked ATP production and disrupted progression to $\mathrm{S}$ phase. We then measured levels of the well-known G1/S transition protein $\mathrm{CyclinD} 1$, and the $\mathrm{G} 2 / \mathrm{M}$ checkpoint regulatory protein CyclinB1 (Schick et al., 2007; Dalton, 2013). We found that CyclinD1, but not CyclinB1, was down-regulated, while PGC- $1 \alpha$ was maintained at a constant level. This result suggests that ATP can regulate cell cycle progression through CyclinD1, and may do so as a consequence of its up-regulation by PGC-1 $\alpha$. We also detected the expression levels of CyclinB1 and CyclinD1 by using antimycin A-treated PGC-1 $\alpha$ cells. The result showed that CyclinB1 and CyclinD1 were down-regulated (Fig. S3).

We also found a relationship between $\mathrm{G} 2 / \mathrm{M}$ phase restriction and CyclinB1 up-regulation in $\mathrm{CH} 1$ PGC- $1 \alpha$ cells. These cells had lower ROS levels than cells in which PGC-1 $\alpha$ was not upregulated. ROS have been identified as important mediators of cell proliferation, cell death, and mitochondrial membrane depolarization (Wood et al., 2003; Marinho et al., 2014). We attempted to find whether $\mathrm{H}_{2} \mathrm{O}_{2}$ enhanced oxidative burst, the transient production of large amounts of ROS, plays a role in controlling cell cycle checkpoints and in inhibition of cell proliferation. Upon treatment with $\mathrm{H}_{2} \mathrm{O}_{2}$, we found that cell proliferation was inhibited and CyclinB1 was downregulated, but CyclinD1 was unaffected.

In summary, our results suggest that mitochondrial complexIII is a target of PGC- $1 \alpha$. Inhibition of ATP production restricted the G1/S phase transition. In contrast, accumulation of ROS involved G2/M phase arrest through down-regulation of CyclinB1. Taken together, these findings suggest that controlling PGC-1 $\alpha$ expression level could represent a reliable and efficient way to maintain ATP and ROS within levels compatible with signaling, while ensuring a robust and reliable energy supply. As such, it holds great potential for treatment of mitochondrial diseases.

\section{Acknowledgements}

We would like to thank all the members of our laboratory for their participation in this study. 


\section{Compliance with ethics guidelines}

Xu-feng FU, Kun YAO, Xing DU, Yan LI, Xiu-yu YANG, Min YU, Mei-zhang LI, and Qing-hua CUI declare that they have no conflict of interest.

This article does not contain any studies with human or animal subjects performed by any of the authors.

\section{References}

Acín-Pérez, P.R., Fernández, S.P., Peleato, M.L., et al., 2008. Respiratory active mitochondrial supercomplexes. Mol. Cell, 32(4):529-539.

http://dx.doi.org/10.1016/j.molcel.2008.10.021

Althoff, T., Mills, D.J., Popot, J.L., et al., 2011. Arrangement of electron transport chain components in bovine mitochondrial supercomplex I1III2IV1. EMBO J., 30(22): 4652-4664. http://dx.doi.org/10.1038/emboj.2011.324

Bertoli, C., Skotheim, J.M., Bruin, R.A., 2013. Control of cell cycle transcription during $\mathrm{G} 1$ and $\mathrm{S}$ phases. Nat. Rev. Mol. Cell Biol., 14(8):518-528. http://dx.doi.org/10.1038/nrm3629

Cannon, B., Houstek, J., Nedergaard, J., 1998. Brown adipose tissue: more than an effector of thermogenesis? Ann. NY Acad. Sci., 856:171-187. http://dx.doi.org/10.1111/j.1749-6632.1998.tb08325.x

Chaturvedi, R.K., Beal, M.F., 2013. Mitochondrial diseases of the brain. Free Radical Biol. Med., 63:1-29. http://dx.doi.org/10.1016/j.freeradbiomed.2013.03.018

Chen, G., Dai, J., Tan, S., et al., 2014. MTERF1 regulates the oxidative phosphorylation activity and cell proliferation in HeLa cells. Acta Biochim. Biophys. Sin., 46(6):512-521. http://dx.doi.org/10.1093/abbs/gmu029

Chen, Q., Yin, G., Stewart, S., et al., 2010. Isolating the segment of the mitochondrial electron transport chain responsible for mitochondrial damage during cardiac ischemia. Biochem. Biophys. Res. Commun., 397(4):656-660. http://dx.doi.org/10.1016/j.bbrc.2010.05.137

Dalton, S., 2013. G1 compartmentalization and cell fate coordination. Cell, 155(1):13-14. http://dx.doi.org/10.1016/j.cell.2013.09.015

Falk, M.J., Shen, L., Gonzalez, M., et al., 2015. Mitochondrial Disease Sequence Data Resource (MSeqDR): a global grass-roots consortium to facilitate deposition, curation, annotation, and integrated analysis of genomic data for the mitochondrial disease clinical and research communities. Mol. Genet. Metab., 114(3):388-396. http://dx.doi.org/10.1016/j.ymgme.2014.11.016

Hahm, E.R., Sakao, K., Singh, S.V., 2014. Honokiol activates reactive oxygen species-mediated cytoprotective autophagy in human prostate cancer cells. Prostate, 74(12): 1209-1221. http://dx.doi.org/10.1002/pros.22837

Lehman, J.J., Barger, P.M., Kovacs, A., et al., 2000. Peroxisome proliferator-activated receptor $\gamma$ coactivator-1 promotes cardiac mitochondrial biogenesis. J. Clin. Invest., 106(7): 847-856.

http://dx.doi.org/10.1172/JCI10268
Lin, J., Handschin, C., Spiegelman, B.M., 2005. Metabolic control through the PGC-1 family of transcription coactivators. Cell Metab., 1(6):361-370. http://dx.doi.org/10.1016/j.cmet.2005.05.004

Löbrich, M., Jeggo, P.A., 2007. The impact of a negligent G2/M checkpoint on genomic instability and cancer induction. Nat. Rev. Cancer, 7(11):861-869. http://dx.doi.org/10.1038/nrc2248

Luckhart, S., Giulivi, C., Drexler, A.L., et al., 2013. Sustained activation of Akt elicits mitochondrial dysfunction to block Plasmodium falciparum infection in the mosquito host. PLoS Pathog., 9(2):e1003180. http://dx.doi.org/10.1371/journal.ppat.1003180

Malumbres, M., Barbacid, M., 2009. Cell cycle, CDKs and cancer: a changing paradigm. Nat. Rev. Cancer, 9(3):153-166. http://dx.doi.org/10.1038/nrc2602

Marinho, H.S., Real, C., Cyrne, L., et al., 2014. Hydrogen peroxide sensing, signaling and regulation of transcription factors. Redox Biol., 2:535-562. http://dx.doi.org/10.1016/j.redox.2014.02.006

McBride, H.M., Neuspiel, M., Wasiak, S., 2006. Mitochondria: more than just a powerhouse. Curr. Biol., 16(14): R551-R560. http://dx.doi.org/10.1016/j.cub.2006.06.054

Meirhaeghe, A., Crowley, V., Lenaghan, C., et al., 2003. Characterization of the human, mouse and rat PGC1 $\beta$ (peroxisome-proliferator-activated receptor- $\gamma$ co-activator $1 \beta)$ gene in vitro and in vivo. Biochem. $J ., 373(\mathrm{Pt} 1)$ : $155-165$. http://dx.doi.org/10.1042/bj20030200

Miraglia, F., Betti, L., Palego, L., et al., 2015. Parkinson's disease and $\alpha$-synucleinopathies: from arising pathways to therapeutic challenge. Cent. Nerv. Syst. Agents Med. Chem., 15(2):109-116. http://dx.doi.org/10.2174/1871524915666150421114338

Pieczenik, S.R., Neustadt, J., 2007. Mitochondrial dysfunction and molecular pathways of disease. Exp. Mol. Pathol., 83(1):84-92. http://dx.doi.org/10.1016/j.yexmp.2006.09.008

Rice, A.C., Ladd, A.C., Bennett, J.P., 2015. Postmortem Alzheimer's disease hippocampi show oxidative phosphorylation gene expression opposite that of isolated pyramidal neurons. J. Alzheimer's Dis., 45(4):1051-1059. http://dx.doi.org/10.3233/JAD-142937

Rohas, L.M., St-Pierre, J., Uldry, M., et al., 2007. A fundamental system of cellular energy homeostasis regulated by PGC-1 $\alpha$. PNAS, 104(19):7933-7938. http://dx.doi.org/10.1073/pnas.0702683104

Schick, V., Majores, M., Fassunke, J., et al., 2007. Mutational and expression analysis of CDK1, cyclinA2 and cyclinB1 in epilepsy-associated glioneuronal lesions. Neuropathol. Appl. Neurobiol., 33(2):152-162. http://dx.doi.org/10.1111/j.1365-2990.2006.00788.x

Shiota, T., Traven, A., Lithgow, T., 2015. Mitochondrial biogenesis: cell-cycle-dependent investment in making mitochondria. Curr. Biol., 25(2):R78-R80. http://dx.doi.org/10.1016/j.cub.2014.12.006

Valero, T., 2014. Mitochondrial biogenesis: pharmacological 
approaches. Curr. Pharm. Des., 20(35):5507-5509. http://dx.doi.org/10.2174/138161282035140911142118

Vartak, R., Porras, C.A., Bai, Y., 2013. Respiratory supercomplexes: structure, function and assembly. Protein Cell, 4(8):582-590. http://dx.doi.org/10.1007/s13238-013-3032-y

Vega, R.B., Huss, J.M., Kelly, D.P., 2000. The coactivator PGC-1 cooperates with peroxisome proliferator-activated receptor $\alpha$ in transcriptional control of nuclear genes encoding mitochondrial fatty acid oxidation enzymes. Mol. Cell. Biol., 20(5):1868-1876.

http://dx.doi.org/10.1128/MCB.20.5.1868-1876.2000

Wallace, D.C., 2005. A mitochondrial paradigm of metabolic and degenerative diseases, aging, and cancer: a dawn for evolutionary medicine. Annu. Rev. Genet., 39(1):359-407. http://dx.doi.org/10.1146/annurev.genet.39.110304.095751

Weinberg, F., Chandel, N.S., 2009. Mitochondrial metabolism and cancer. Ann. NY Acad. Sci., 1177(1):66-73. http://dx.doi.org/10.1111/j.1749-6632.2009.05039.x

Won, J.C., Park, J.Y., Kim, Y.M., et al., 2010. Peroxisome proliferator-activated receptor- $\gamma$ coactivator $1-\alpha$ overexpression prevents endothelial apoptosis by increasing ATP/ADP translocase activity. Arterioscler. Thromb. Vasc. Biol., 30(2):290-297. http://dx.doi.org/10.1161/ATVBAHA.109.198721

Wood, Z.A., Poole, L.B., Karplus, P.A., 2003. Peroxiredoxin evolution and the regulation of hydrogen peroxide signaling. Science, 300(5619):650-653. http://dx.doi.org/10.1126/science.1080405

Wu, Z., Puigserver, P., Andersson, U., et al., 1999. Mechanisms controlling mitochondrial biogenesis and respiration through the thermogenic coactivator PGC-1. Cell, 98(1):115-124 http://dx.doi.org/10.1016/S0092-8674(00)80611-X

Xiong, W., Jiao, Y., Huang, W., et al., 2012. Regulation of the cell cycle via mitochondrial gene expression and energy metabolism in HeLa cells. Acta Biochim. Bioph. Sin., 44(4):347-358.

http://dx.doi.org/10.1093/abbs/gms006

Xu, H., Lyu, S., Xu, J., et al., 2015. Effect of lipopolysaccharide on the hemocyte apoptosis of Eriocheir sinensis. $J$. Zhejiang Univ.-Sci. B (Biomed. \& Biotechnol.), 16(12): 971-979. http://dx.doi.org/10.1631/jzus.B1500098

Zhang, Y., Ba, Y., Liu, C., et al., 2007. PGC-1 $\alpha$ induces apoptosis in human epithelial ovarian cancer cells through a PPAR $\gamma$-dependent pathway. Cell Res., 17(4): 363-373.

http://dx.doi.org/10.1038/cr.2007.11

\section{List of electronic supplementary materials}

Fig. S1 Immunofluorescence picture of CyclinD1 and CyclinB1 in PB, PGC-1 $\alpha$, and Si cells

Fig. S2 Mitochondrial content indicated by MitoTracker Green fluorescence (analyzed by flow cytometry)

Fig. S3 Change of CyclinD1/B1 levels in CH1-PGC-1 $\alpha$ after $24 \mathrm{~h}$ of antimycin A treatment

\section{中文概要}

\section{题 目: PGC-1 $\alpha$ 在 CH1 细胞中通过 ATP 和 ROS 调控} 细胞周期

目 的: 探讨在 $\mathrm{CH} 1$ 细胞中过氧化物酶体增殖物受体 $\gamma$ 共激活因子 $1 \alpha$ (PGC- $1 \alpha)$ 调控细胞周期时三磷 酸腺苷 (ATP) 和活性氧 ( ROS) 的作用机制。

创新点: 构建了稳定表达 PGC- $1 \alpha$ 的 CH1 细胞株, 并系统 地研究了 PGC- $1 \alpha$ 调控细胞周期是通过 ATP 和 ROS 调节 CyclinD1 和 CyclinB1 的行使功能。

方 法: 以慢病毒质粒 $\mathrm{pBABE}$ 为载体构建了 $\mathrm{PGC}-1 \alpha$ 稳 定表达的 CH1 PGC-1 $\alpha$ 细胞株（PGC-1 $\alpha$ ），同时 转染空质粒 $\mathrm{pBABE}$ 作为对照 (PB), 结合 RNA 干扰 CH1 PGC-1 $\alpha$ 中 PGC-1 $\alpha$ 的过表达 ( $\mathrm{Si})$, 测定了 ATP 和 ROS 水平。用流式细胞术检测了 细胞周期和免疫印迹检测了 CyclinB1/D1 的表达, 并进一步分别用寡霉素抑制 PGC- $1 \alpha$ 细胞中的 ATP 生成, 用 $\mathrm{H}_{2} \mathrm{O}_{2}$ 处理细胞以增加外源 ROS 水 平。然后检测 ATP 和 ROS 改变后, 对 CyclinB1/D1 表达及细胞周期的影响, 以明确 ATP 和 ROS 是 否参与 PGC- $1 \alpha$ 对细胞周期的调控作用。

结 论: 本实验成功构建了稳定表达 PGC- $1 \alpha$ 的细胞株 (图 1 和图 2a), 与 PB 对照和 RNA 干扰 PGC- $1 \alpha$ 比较, 过表达 PGC- $1 \alpha$ 具有升高 ATP、降低 ROS 和促进细胞周期的作用（图 3 和图 4)。进一步 用臭霉素抑制 ATP 合成后发现 CyclinD1 明显下 调（图 5), 而加入 $\mathrm{H}_{2} \mathrm{O}_{2}$ 增加外源 ROS 后发现 CyclinB1 显著上调（图 6)。通过本实验我们提 出 PGC- $1 \alpha$ 调控细胞周期是通过升高 $\mathrm{ATP}$ 水平抑 制 CyclinD1 表达和降低 ROS 水平促进 CyclinB1 表达来实现。

关键词：过氧化物酶体增殖物受体 $\gamma$ 共激活因子 $1 \alpha$ (PGC-1 $1 \alpha)$; 线粒体; 氧化磷酸化; 细胞周期; CyclinD1; CyclinB1 